\section{Epidural Spinal Cord Stimulation for Neuropathic Pain: Algology Unit in Bagcilar Training and Research Hospital Data Collection and Analysis}

\author{
Abdullkadir Yektaş \\ Abdulkadir Yektaş, Bagcilar Training and \\ Research Hospital, Istanbul, Bagcilar, Turkey
}

Corresponding author: Abdulkadir Yektaş

झ akyektas722000@yahoo.co.uk

Bagcilar Training and Research Hospital, Istanbul, Bagcilar, Turkey.

Tel: 9005053881884

Citation: Yektaş A. Epidural Spinal Cord Stimulation for Neuropathic Pain: Algology Unit in Bagcilar Training and Research Hospital Data Collection and Analysis. Spine Res. 2015, 2:2.

\section{Introduction}

Neuropathic pain is a chronic condition, challenging to treat and deeply correlated with psychological aspect: it can be codetermined by emotional and behavioural factors, and it can play an important role in determining depression or in decreasing quality of life. Spinal cord stimulation (SCS) is a therapeutic option in patients with chronic/neuropathic pain with different aetiologies (i.e. failed back surgery syndrome (FBSS), chronic spine pathologies and neuropathic diseases) [1-5] not eligible for surgery and refractory to any pharmacological and other conservative treatment [6]. 
SCS is theoretically based on the Gate Control Theory developed by Melzack and Wall [7], which explains physiopathology of such conditions as hyperalgesia, painful anaesthesia and spontaneous pain. The loss of large peripheral nerve fibres after a nerve injury produced a drop in the inhibition on the slow $C$-fibres inputs causing the open-gate condition responsible of these types of pain.

SCS has demonstrated to be more effective on neuropathic pain compared with nociceptive pain [6]. The best result of this technique were initially observed in patients affected by postherpetic neuralgia and vasculopathic pain, with good pain relief in more than $60 \%$ of patients [5]. The role of SCS in treating lowback pain was debated in the past because of the reduction of pain control at long-term follow-up $[2,5]$. Some authors demonstrated that SCS associated with standard pharmacological therapy could reduce chronic pain more than common pharmacological therapies used alone and it could improve quality of life and patients return to their own occupation $[8,9]$.

Various authors identified the important role of psychological factors on pain modulation and on effectiveness of SCS $[5,7,10$ 12]. Thanks to technological improvements of both leads and implantable pulse generators (IPG $)$, and the more accurate selection of patients, SCS has gained increasing reliability in the armamentarium of surgical and analgesic techniques to control pain when conservative and other surgical treatments failed. FBSS is presently the main indication for SCS, followed by complex regional pain syndrome (CRPS), intractable angina pectoris and pain due to peripheral vascular disease [13-15]. Further indications comprise painful conditions related to peripheral nerve chronic diseases, in which this technique should be preferred to more invasive and ablative treatments $[1,4,5]$.

Usually patients are submitted to psychological evaluation and quality-of-life assessment before undergoing the trial period for 15-21 days [10].

According to currently available evidence, the role of SCS in FBSS is particularly demonstrated in those conditions with prevalent lower-limb pain [16], with best results in unilateral leg pain $[5,8,17,18]$. Some authors reported therapy-effectiveness and cost-effectiveness of SCS versus reoperation in FBSS, assuming the correct selection of patients and the importance of trial period. SCS is often used after all the surgical procedures available of spine pathologies, with possible reduction of its potential therapeutic role [19-21]. Furthermore, prevalent back pain has a reported lower response to SCS, which might be related to the nociceptive component of pain in this group of patient $[6,19,20]$.

The aim of this data collection is to enforce evidence of SCS effectiveness in treating neuropathic chronic pain.

\section{Materials and Methods}

Between September 2012 and September 2014, 22 subjects were assessed in algology polyclinic in Bağcılar Training and Research Hospital. Each patient gave written informed consent for data collection and analysis.

All patients eligible to SCS therapy were considered for analysis. We analysed the characteristics of patients in terms of base-line features, implant indications, pain distribution, duration of pain, type of implanted device and type of surgical procedure.

Patients who underwent the permanent implant were evaluated after $6,12,18$ and 24 months. In the present paper, we analysed SCS outcomes after 24 months.

\section{Pre-implant data collection}

Each patient was submitted to a pre-implant data collection form to evaluate the features of chronic pain. Within the total population of 22 patients, 11 were women (50\%) and 11 men (50\%). The mean age of patients at the moment of permanent implant was $60.50 \pm 14.98$ years old (range, $32-85$ ) and the mean pain duration was 24 months (range, 12-48 months).

Prevalent pain was localized to the lower limbs in 12 patients (75\%), the lower back (also defined as 'axial pain) in 8 patients (49\%) and the upper limbs in the remaining 2 patient (Table 1). The prevalent visual analogue scale (VAS) value is determined as the greater baseline value between the axial VAS value and lower-limb VAS value for each patient.

The mean onset VAS value was $9 \pm 1.27$ for lower limb pain and $8.75 \pm 1.39$ for axial pain.

Pain was associated with one or more accompanying symptoms in 10 patients $(63.4 \%)$, including numbness $(n=5,50 \%)$, weakness $(n=4,40 \%)$ and other symptoms $(n=5,50 \%)$

Before implant, we asked the patients to list previous noninvasive therapies they had undergone for neuropathic pain, and currently ongoing pharmacological therapies. All patients (100\%) had ongoing both pharmacological therapy and nonpharmacological therapy (Table 2).

Patients' weight and the corresponding body mass index (BMI) were analysed, showing a mean weight $76.4 \mathrm{~kg}$ (range, 45-120 $\mathrm{kg}$ ) and a mean BMI of 28 (range, 20-34). With respect to smoking habit, we found that all patients non-smokers. Prevalence of common disease, i.e. hypertension and diabetes, was comparable to the general population $[21,22]$.

\section{Implant indications}

Patients' selection was done by each neurosurgeon during out patients clinic, following exclusion criteria reported in literature [6]:

Table 1 Localisation of prevalent pain in relation to the trial period.

\begin{tabular}{|cc|}
\hline Painful area & $9(40.90 \%)$ \\
\hline Prevalent axial & $8(36.36 \%)$ \\
\hline Prevalent lower limbs & $1(4.54 \%)$ \\
\hline Prevalent upper limbs & $9(40.90 \%)$ \\
\hline Low back & $2(9.09 \%)$ \\
\hline $\begin{array}{c}\text { Low back and one inferior } \\
\text { extremity }\end{array}$ & $6(27.27 \%)$ \\
\hline Low back and both inferior & $3(13.63 \%)$ \\
\hline extremities & $3(13.63 \%)$ \\
\hline One inferior extremities & $1(4.54 \%)$ \\
\hline Both inferior extremities & \\
\hline Other (Upper limbs) &
\end{tabular}


Table 2 Rates of primary pathologies and previous non-invasive treatments.

\begin{tabular}{|c|c|}
\hline Primary pathology & No. of patients \\
\hline Discectomy (Multiple surgery) & $4(18.18)$ \\
\hline Laminectomy (Single surgery) & $2(9.09 \%)$ \\
\hline Laminectomy (Multiple surgery) & $2(9.09 \%)$ \\
\hline Lumbar fusion (Multiple surgery) & $3(13.63 \%)$ \\
\hline $\begin{array}{c}\text { Lumbar spine pathologies (Without } \\
\text { previous surgery) }\end{array}$ & $7(31.81)$ \\
\hline Others & \\
\hline Peripheral nerve injury & $2(9.09)$ \\
\hline Vertebrectomy/vertebral trauma & $1(4.54)$ \\
\hline Limb amputation & $1(4.54)$ \\
\hline Previous non-invasive therapies & \\
\hline Pharmacological therapies & 22 \\
Opioids & 22 \\
\hline NSAIDS & 22 \\
\hline Antidepressants & 22 \\
\hline Anticonvulsants & 22 \\
\hline Sreroids & 22 \\
\hline Other Drugs & 22 \\
\hline PBSS: Failed back surgery syndrome; NSAIDS: Non-steroidal \\
anti-inflammatory drugs; TENS: Transcutaneous electrical nevre \\
stimulation. $\quad$ \\
\hline Radicular block
\end{tabular}

1. Complete lesions of the dorsal column (i.e. total paraplegia).

2. Presence of pathological conditions (i.e. multiple sclerosis) needs a magnetic resonance imaging (MRI) follow-up.

3. Patients with chronic pain who have not tried noninvasive therapeutic options, pharmacological and nonpharmacological (i.e. physiotherapy, TENS).

4. Patient with chronic pain associated with a pathological condition that could be surgically treated.

5. Coagulopathy or immunodeficiency disorders, which could interfere with neuromodulation procedures.

6. Major psychiatric disorders, drug or alcohol abuse, existing drug habituation problems, poor compliance or low/absent possibility to understand the therapy.

7. Cardiac pace-maker (PM) or implantable cardiac defibrillator (ICD).

The pathologies affecting our patients are summarized in Table 2.

All patients were suffering from neuropathic pain, localized to the lower limbs, lower back or both. In FBSS group (7 patients, 49\%), 7 patients (49\%) underwent multiple spine surgeries, 3 patients (19\%) had single or multiple discectomies and 3 patients $(22.72 \%)$ were subjected to instrumented spine surgery (Table 3).

Eight patients (50\%) suffered for chronic neuropathic pain of different origin and never had any spine surgery.

\section{Technical notes}

We used two types of epidural leads 1. (Medtronic, Mineapoli, MN, USA): percutaneous leads (Octet electrode lead) and St jude medical, USA): Percutaneous leads (8-electrode-S-series).

Percutaneous leads of Medtronic are inserted into the epidural space with a needle-guide and without opening the facia. 2 . Percutaneous leads of S-series (Lamitrode) are inserted into the epidural space with a needle-guide by epiducer and without opening the facia. In both of the procedure both a lateral X-ray and A-P X-ray scan was used to control the spine level, (Electrode was placed to thoracolomber epidural space which entrance was $\mathrm{L}_{2-3}$ intervertebral space and the tip of the electrode was middle of the $T_{8}$ vertebral body in the A-P X-ray) (Figures 1 and 2). The number and shape of leads were selected according to the extension of painful area.

Table 3 Reduction of VAS, reported as median (minimum-maximum) (range) (Prevalent VAS score explained in Materials and methods) (Medium \pm Min-Max).

\begin{tabular}{|c|c|c|c|}
\hline Parameters & Baseline & 6 months & P values \\
\hline Axial VAS & $10(8-10)$ & $7(2-9)$ & 0.001 \\
\hline Lower limbs VAS & $10(7-10)$ & $7(2-9)$ & 0.001 \\
\hline Prevalent VAS & $10(7-10)$ & $7.5(0-9)$ & 0.001 \\
\hline & Baseline & 12 months & P Values \\
\hline Axial VAS & $10(8-10)$ & $5(2-6)$ & $\mathrm{P}<0.001$ \\
\hline Lower limbs VAS & $10(7-10)$ & $3(0-7)$ & $\mathrm{P}<0.001$ \\
\hline Axial VAS & Baseline & 18 months & $\mathrm{P}$ Values \\
\hline Lower limbs VAS & $10(8-10)$ & $5(2-6)$ & $\mathrm{P}<0.001$ \\
\hline Prevalent VAS & $10(7-10)$ & $3(0-5)$ & $\mathrm{P}<0.001$ \\
\hline Axial VAS & $10(7-10)$ & $3(0-5)$ & $\mathrm{P}<0.001$ \\
\hline Lower limbs VAS & $10(8-10)$ & $5(2-6)$ & $\mathrm{P}<0.001$ \\
\hline Prevalent VAS & $10(7-10)$ & $2(0-5)$ & $\mathrm{P}<0.001$ \\
\hline Prevalent VAS & $10(7-10)$ & $2(0-5)$ & $\mathrm{P}<0.001$ \\
\hline
\end{tabular}

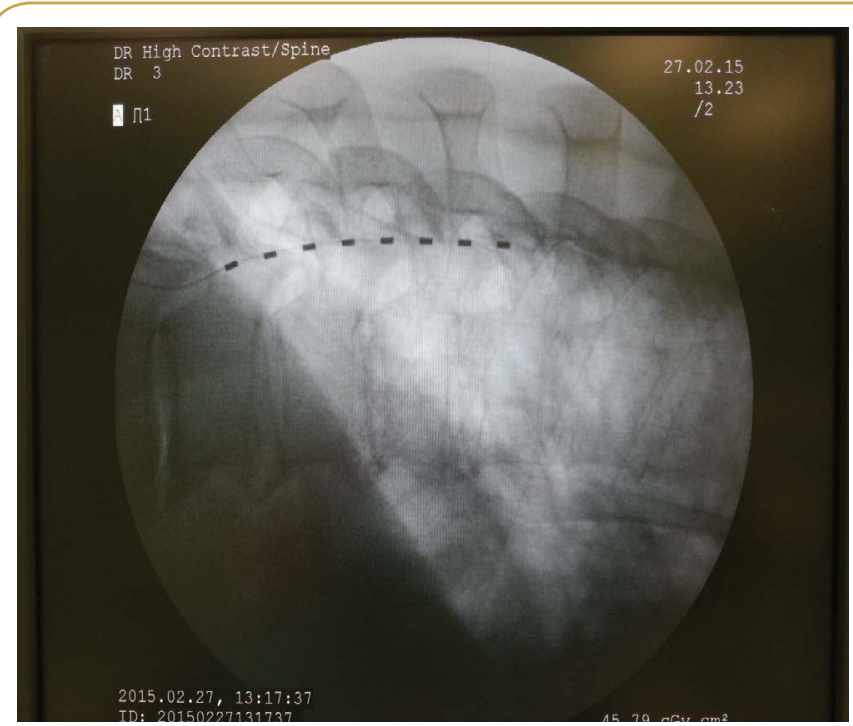

Figure 1 The lateral position of the electrode in the X-Ray scan. 


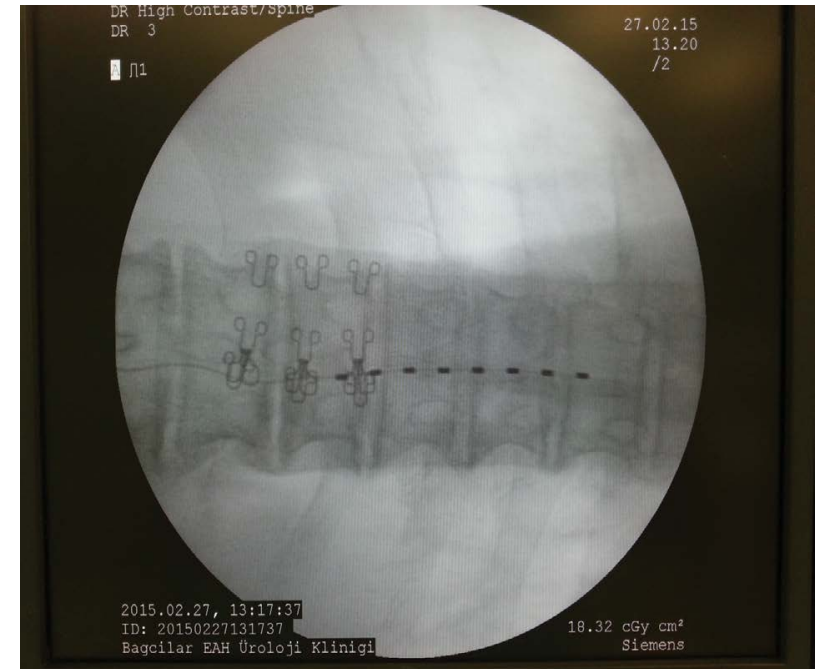

Figure 2 The Antero-Posterior position of the electrode in the X-Ray scan.

Within the 22 patients implanted, 8 (36.36\%) were subjected to the octet and 14 (63.63\%) to the S-series (Lamitrode) procedure.

Leads were connected through an extension cable to rechargeable IPGs and a few non rechargeable IPGs.

We performed the temporary implant 22 patients (100\%) connecting the lead to an external pulse generator for a trial period of 21-90 days. Type and pattern of stimulation was continuous standard stimulation during trial period and therapy period. VAS values of patients were not $50 \%$ lower than baseline VAS values of patients in which trial electrode which removed after trial period.

The temporary implant was performed with the patient in the prone position under local anesthesia and deep sedation. Sedation was reduced after positioning the lead on the dural surface to evaluate pain coverage and acceptance of stimulation.

\section{Follow-up}

We analysed results after 6-12-18-24 months of stimulation and we compared the outcomes between onset VAS values and respectively 6-12-18-24 months VAS values.

The present analysis evaluates results of SCS therapy after 6-1218-24 months from permanent implant in terms of:

1. Pain relief, pain coverage and presence of associated symptoms

2. Ongoing pharmacological or other conservative therapies

3. Adverse events and changes in stimulation settings

4. Hamilton's scale for depression

5. Oswestry disability index (ODI)

6. Short form-36 (SF 36) health survey

7. Euro quol dimensions (EQ5D) score
EQ5D score evaluate health-related quality of life with a questionnaire focused on five points (mobility, self-care, usual activities, pain/discomfort, anxiety/depression).

\section{Statistical methods}

Descriptive statistics were reported as mean and standard deviation for normally distributed continuous variables, or median with 25-75 percentiles in case of skewed distribution. Normality was assessed by means of Shapiro-Walk test. Absolute and relative frequencies are reported for categorical variables.

Statistical comparisons of continuous variables were performed by paired-samples $T$ test or non-parametric test (Wilcoxon ranksum test) for normal and non-normal distributions, respectively.

In order to calculate the percentage of VAS improvement, difference between follow-up and base-line was divided by baseline value.

All two-tailed $P$ value $<0.05$ was considered statistically significant. SPSS 11.5 for Windows was used for statistical analysis.

\section{Results}

All patients were affected by neuropathic pain, mostly localized to one or both lower limbs, with radicular localization, and associated with low-back pain in several cases. In a few cases patients were suffering from isolated axial pain or other type of pain. The rate of patients who were suffering from prevalent lower-limb pain were $50 \%$.

\section{Clinical results: After trial period}

Four patients had removal of temporary device after the trial period for the following reasons:

1. Non-responders, 2 patients

2. Infection 2 patients

IPGs removed 3 months after trial period in one patient and also 6 months after trial period in one patient.

Analyzing VAS score (prevalent, axial and lower limbs pain) compared between baseline and 6-12-18-24 months of stimulation. Reduction of VAS (after 6-12-18-24 months) reached

Table 4 Quality of life outcomes (Mean \pm SD).

\begin{tabular}{|c|c|c|c|}
\hline Parameter & Baseline & 12 months & $P$ values \\
\hline EQ5D Index & $0.2 \pm 0.18$ & $0.76 \pm 0.12$ & $<0.001$ \\
\hline EQ5D VAS & $4.2 \pm 0.12$ & $1.4 \pm 0.22$ & $<0.001$ \\
\hline ODI & $41.7 \pm 9.87$ & $17.6 \pm 14.3$ & $<0.001$ \\
\hline SF-36 PCS & $25.4 \pm 9.3$ & $40.4 \pm 8.6$ & $<0.001$ \\
\hline \multirow[t]{2}{*}{ SF-36 MCS } & $42.7 \pm 9.4$ & $40.1 \pm 10.7$ & 0.378 \\
\hline & Baseline & 24 months & $P$ values \\
\hline EQ5D Index & $0.2 \pm 0.18$ & $0.72 \pm 0.22$ & $<0.001$ \\
\hline EQ5D VAS & $4.2 \pm 0.12$ & $1.6 \pm 0.33$ & $<0.001$ \\
\hline ODI & $41.7 \pm 9.87$ & $14.9 \pm 12.7$ & $<0.001$ \\
\hline SF-36 PCS & $25.4 \pm 9.3$ & $42.4 \pm 10.5$ & $<0.001$ \\
\hline SF-36 MCS & $42.7 \pm 9.4$ & $38.3 \pm 8.9$ & 0.456 \\
\hline \multicolumn{4}{|c|}{ PCS: Physical Score; MCS: Mental Component Score } \\
\hline
\end{tabular}


statistical significance in patients for lower limb pain and for prevalent pain $(P<0.001)$. Reduction of axial pain VAS (after 1218-24 months) could be reported as statistically significant in the patients $(P<0.001)$, reduction of axial pain in 6 . months only $(p=0.001)$

Considering quality of life improvement at 12-24 months, ODI, Physical Component score (PCS) of SF36 questionnaire and EQ5D questionnaires significantly improved in patients $(P<0.001$, $\mathrm{P}<0.001$ ), SF36 Mental Component Score (MCS) questionnaire did not significantly improve in patients $(P=0.378, P=0.456)$ (Table 4).

\section{Adverse events and causes of device removal}

Nine complications occurred in 9 patients (45\% of implanted subjects) and were grouped as technical $(n=6)$ and clinical $(n=3)$.

All clinical complications occurred in the patients and included one case of infection, one loss of efficacy. Six of technical complications occurred in the patients and included one connecting cable fractures, three early battery depletions, one lead dislocation and one lead fractures.

Six patients underwent revision surgery: One lead connection repositioning, two lead replacements and lead exploration, tree IPG replacement, (One case each).

Six of the 22 patients (27.27\%) were explanted after permanent implant for different reasons:

1. Infection of the device, $1(4.54 \%)$

2. Loss of clinical efficacy, 1 (4.54\%)

3. Uncomfortable psychological aspects, 2 (9.09\%)

4. Referred resolution of clinical symptoms (with system switched off), 2 (9.09\%)

\section{Discussion}

We discuss about three aspects of SCS implant: Pain reduction, Quality of life and Complication

\section{Pain reduction}

In the literature we found a significant reduction of VAS at 1 year, ranging from $39.3 \%[23,24]$ to $73.7 \%$ and $79.8 \%$ of the patients included [15].

Evidence in obtaining primary outcome is reported as variable: Kumar et al. [8] reported a rate of 58\% after 6 months, which decreases to $38 \%$ after 24 months of stimulation [25]. Sears et al. [24] reported good primary outcome at 12 months in $42.9 \%$ of patients, with best results in CRPS in comparison to FBSS. In the same study, the degree of satisfaction (indexed as the rate of patients who would undergo the same procedure again) was reported as $>70 \%$ in patients with FBSS and CPRS.

We compared our results with the main studies of the last 20 years in which primary outcome was defined as reduction of VAS $>50 \%$ after 12 months (Table 5) [8,15-17,24-33]. We had VAS value that $50 \%$ lower than baseline VAS value for all patients. Slaven et al. [15] reported a mean reduction of VAS $\sin$ a 1-10 scale) of 3.5 after 1 year of stimulation analyzing two long-term studies.

Reduction of VAS after 12-24 months was as much as in the group of patients treated for prevalent axial pain in comparison to lower limbs pain group (Table 3).

No statistically significant differences were found between lower limbs pain group and axial pain group.

\section{Quality of life}

We analysed quality of life outcomes using three rating scales: ODI, EQ5D and SF36 questionnaire and we also tested patients with Hamilton's scale for depression.

It is generally known that SCS has good outcomes in terms of return to work and patien satisfaction $[8,15,24,25,30,34]$. Patient satisfaction on pain relief is reported to be $66 \%$ after 6 months [8] and $62 \%$ after 24 months [25], while patient satisfaction for the treatment is $93 \%$ after 6 months [8] and $86 \%$ after 24 months [25].

Kumar et al. [8] reported a statistically significant difference after 6 months between treatment and conservative therapies in the ODI, physical function and bodily pain.

In our analysis, we also found a general improvement of quality of life in terms of ODI, EQ5D and SF36 questionnaires. ODI improvement after 12 and 24 months was greater than $50 \%$ from baseline in $100 \%$ of patients.

Given the different assessment scales and lack of general consensus on the most appropriate parameters for therapy efficacy evaluation in terms of quality of life, is anyway difficult to perform a close comparison of different studies.

\section{Complications and causes of explant}

Starting from initial population of 22 patients, only 4 patients $(18.18 \%)$ decided not to have the permanent implant after the trial period, reporting poor efficacy of the SCS. One patients refused the permanent implant for personal reasons and one patient was explanted due to infection.

Analyzing clinical outcomes in the 18 patients that underwent permanent SCS implant, we want to emphasize that only 2 (9.09\%) patients were explanted because of loss of satisfaction or discomfort. In the literature we found a reduction of effectiveness rated $6 \%$ at 1 year [15] and $11 \%$ at 24 months [25].

Complications of SCS have been summarized in different classifications, and some authors define them as neurological, non-neurological and hardware related $[8,25,35]$.

Some previous studies aimed at analyzing complications and costeffectiveness reported an overall rate of SCS related complications of $35 \%$ [36] or $32 \%$ of device related complications [8]. In a review of 707 cases, the rate of hardware-related complications (including lead migrations, lead connection failure and lead break) was $38.1 \%$, while the rate of documented infections was $4.5 \%$ with one case epidural infection [35]. One study about the 11 year experience with SCS reported an infection rate of $4.9 \%$ [37].

Our overall complications rate $(27.27 \%)$ is comparable $[34,38,39]$ that reported in the main literature (Table 5).

\section{Conclusion}

Our results enforce the evidence of efficacy of SCS therapy in terms of pain reduction, patient satisfaction and quality of life, according to previously published studies. 
Table 5 Comparison of our analysis with literature (Studies in which VAS reduction $>50 \%$ was used as primary outcome).

\begin{tabular}{|c|c|c|c|c|c|c|c|c|}
\hline Study & Pain Aetiology & Patients, Total & $\begin{array}{l}\text { Patients } \\
\text { Implanted }\end{array}$ & $\begin{array}{l}\text { Patientswith } \\
\text { Primary } \\
\text { Outcomes at } \\
12 \text { Months }\end{array}$ & ODI Baseline & ODI 12 Months & SF36 & $\begin{array}{c}\text { Complication } \\
\text { Rate }\end{array}$ \\
\hline $\begin{array}{c}\text { Kupers et al. } \\
\text { [26] }\end{array}$ & $\begin{array}{c}\text { FBSS, CRPS } \\
\text { neuropathic, } \\
\text { PVD }\end{array}$ & 700 & $52 \%$ & & & & & \\
\hline $\begin{array}{l}\text { Van de cleft } \\
\text { (1994) }\end{array}$ & & 116 & 84 & $54 \%$ & & & & \\
\hline $\begin{array}{c}\text { Burchiel et al. } \\
\text { [17] }\end{array}$ & FBSS & $\begin{array}{c}219 \\
\text { (6 centres) }\end{array}$ & 182 & $55 \%$ & $\begin{array}{c}0.542 \\
(S D 0.14)\end{array}$ & $\begin{array}{c}0.469 \\
(S D 0.2)\end{array}$ & & $17 \%$ \\
\hline Kumar et al. [2] & $\begin{array}{l}\text { FBSS, CRPS, } \\
\text { other } \\
\text { neuropathic } \\
\text { PVD }\end{array}$ & 235 & 189 & $59 \%$ & & & & \\
\hline $\begin{array}{l}\text { Van Buyten et } \\
\text { al. [32] }\end{array}$ & FBSS & 254 & 217 & $68 \%$ & & & & \\
\hline Dario et al. [13] & FBSS & 49 & & $71 \%$ & & & & \\
\hline $\begin{array}{l}\text { North et al. } \\
{[28]}\end{array}$ & FBSS & 24 & & $47 \%$ & & & & \\
\hline Taylor [29] & $\begin{array}{c}\text { FBSS,CRPS, } \\
\text { other } \\
\text { neuropathic }\end{array}$ & $\begin{array}{c}3313 \\
\text { (65 studies) } \\
1992\end{array}$ & 1992 & $62 \%(56-69 \%)$ & & & & $18 \%$ \\
\hline $\begin{array}{c}\text { Kumar e t al. } \\
{[8,9]}\end{array}$ & FBSS & 52 & & $\begin{array}{c}58 \% \\
\text { (6 months); } \\
48 \% \\
\text { (12 months) }\end{array}$ & 52 & $\begin{array}{c}44.9 \\
\text { (6 months) }\end{array}$ & & $45 \%$ \\
\hline $\begin{array}{c}\text { Turner et al. } \\
\text { [31] }\end{array}$ & $\begin{array}{c}\text { FBSS, CPRS, } \\
\text { other } \\
\text { neuropathic }\end{array}$ & & 51 & $15 \%$ & & & & $16 \%$ \\
\hline Sears [24] & FBSS, CRPS & & 52 & $42.50 \%$ & & & & \\
\hline $\begin{array}{c}\text { Slavin et al. } \\
\text { [15] }\end{array}$ & $\begin{array}{l}\text { FBSS, other } \\
\text { neuropathic }\end{array}$ & $\begin{array}{c}334 \\
\text { (4 studies) }\end{array}$ & $\begin{array}{c}300 \\
\text { (2 out of } 4 \\
\text { studies) }\end{array}$ & $\begin{array}{c}3 \text { months: } \\
75.4 \% \text {, } \\
12 \text { months } \\
76.3 \%\end{array}$ & & & $\begin{array}{l}\text { Improving: } \\
3 \text { months } \\
77.9 \%, \\
75 \% \text { at } 1 \text { year }\end{array}$ & \\
\hline Colombo [39] & $\begin{array}{l}\text { FBSS,CRPS, } \\
\text { Other } \\
\text { neuropathic }\end{array}$ & 122 & 106 & $63.8 \%$ & 47.7 (SD19.0) & 24.9 (SD19.0) & $P<0.001$ & $14 \%$ \\
\hline Our Analysis & $\begin{array}{l}\text { FBSS, other } \\
\text { neuropathic }\end{array}$ & 22 & 18 & $\begin{array}{c}12 \text { months } \\
100 \% \\
24 \text { months } \\
100 \%\end{array}$ & $42.7(9.4)$ & $\begin{array}{c}17.6 \text { (SD14.3) } \\
24 \text { months: } \\
14.9 \text { (SD12.7) }\end{array}$ & $P<0.001$ & $27.27 \%$ \\
\hline
\end{tabular}




\section{References}

1 Dworkin RH, O'Connor AB, Kent J, Mackey SC, Raja SN, et al. (2013) Interventional management of neuropathic pain: NeuPSIG recommendations. Pain 154: 2249-2261.

2 Kumar K, Toth C, Nath RK, Laing P (1998) Epidural spinal cord stimulation for treatment of chronic pain--some predictors of success. A 15-year experience. Surg Neurol 50: 110-120.

3 Landau B, Levy RM (1993) Neuromodulation techniques for medically refractory chronic pain. Annu Rev Med 44: 279-287.

4 Magimbi AS, de Leon-Casasola OA (2004) Spinal cord stimulation. Tech Reg Anesth Pain Manag 4: 132-136.

5 Meglio M, Cioni B, Rossi GF (1989) Spinal cord stimulation in management of chronic pain. A 9-year experience. J Neurosurg 70: 519-524.

6 Health Quality Ontario (2005) Spinal cord stimulation for neuropathic pain: an evidence based analysis. On tHealth Technol Assess Ser 5: 1-78.

7 Melzack R, Wall PD (1965) Pain mechanisms: a new theory. Science 150: 971-979.

8 Kumar K, Taylor RS, Jacques L, Eldabe S, Meglio M, et al. (2007) Spinal cord stimulation versus conventional medical management for neuropathic pain: a multicentre randomised controlled trial in patients with failed back surgery syndrome. Pain 132: 179-188.

9 Manca A, Kumar K, Taylor RS, Jacques L, Eldabe S, et al. (2008) Quality of life, resource consumption and costs of spinal cord stimulation versus conventional medical management in neuropathic pain patients with failed back surgery syndrome (PROCESS trial). Eur J Pain 12: 1047-1058.

10 Atkinson L, Sundaraj SR, Brooker C, O'Callaghan J, Teddy P, et al. (2011) Recommendations for patient selection in spinal cord stimulation. J Clin Neurosci 18: 1295-1302.

11 North RB, Wetzel FT (2002) Spinal cord stimulation for chronic pain of spinal origin: a valuable long-term solution. Spine 27: 2584-2591.

12 Sparkes E, Raphael JH, Duarte RV, LeMarchand K, Jackson C, et al. (2010) A systematic literature review of psychological characteristics as determinants of outcome for spinal cord stimulation therapy. Pain 150: 284-289.

13 de Leon-Casasola OA (2009) Spinal cord and peripheral nerve stimulation techniques for neuropathic pain. J Pain Symptom Manage 38: S28-38.

14 Reverberi C, Dario A, Barolat G (2013) Spinal cord stimulation (SCS) in conjunction with peripheral nerve field stimulation (PNfS) for the treatment of complex pain in failed back surgery syndrome (FBSS). Neuromodulation 16: 78-82.

15 Slavin KV, Vaisman J, Pollack KL, Simopoulos TT, Kowlowitz E, et al. (2013) Treatment of chronic, intractable pain with a conventional implantable pulse generator: a meta-analysis of 4 clinical studies. Clin J Pain 29: 78-85.

16 Dario A, Fortini G, Bertollo D, Bacuzzi A, Grizzetti C, et al. (2001) Treatment of failed back surgery syndrome. Neuromodulation 4: 105-110.

17 Burchiel KJ, Anderson VC, Brown FD, Fessler RG, Friedman WA, et al. (1996) Prospective, multicenter study of spinal cord stimulation for relief of chronic back and extremity pain. Spine 21: 2786-2794.

18 Frey ME, Manchikanti L, Benyamin RM, Schultz DM, Smith HS, et al. (2009) Spinal cord stimulation for patients with failed back surgery syndrome: a systematic review. Pain Physician 12: 379-397.
19 Krames ES, Monis S, Poree L, Deer T, Levy R (2011) Using the SAFE principles when evaluating electrical stimulation therapies for the pain of failed back surgery syndrome. Neuromodulation 14: 299-311.

20 North RB, Kumar K, Wallace MS, Henderson JM, Shipley J, et al. (2011) Spinal cord stimulation versus re-operation in patients with failed back surgery syndrome: an international multicenter randomized controlled trial (EVIDENCE study). Neuromodulation 14: 330-335.

21 Poree L, Krames E, Pope J, Deer TR, Levy R, et al. (2013) Spinal cord stimulation as treatment for complex regional pain syndrome should be considered earlier than last resort therapy. Neuromodulation 16 : 125-141.

22 Pereira M, Lunet N, Azevedo A, Barros H (2009) Differences in prevalence, awareness, treatment and control of hypertension between developing and developed countries. J Hypertens 27: 963975.

23 (2013) The global dominance of diabetes. Lancet 382: 1680.

24 Sears NC, Machado AG, Nagel SJ, Deogaonkar M, Stanton-Hicks M, et al. (2011) Long-term outcomes of spinal cord stimulation with paddle leads in the treatment of complex regional pain syndrome and failed back surgery syndrome. Neuromodulation 14: 312-318.

25 Kumar K, Taylor RS, Jacques L, Eldabe S, Meglio M, et al. (2008) The effects of spinal cord stimulation in neuropathic pain are sustained: a 24-month follow-up of the prospective randomized controlled multicenter trial of the effectiveness of spinal cord stimulation. Neurosurgery 63: 762-770.

26 Kupers RC, Van den Oever R, Van Houdenhove B, Vanmechelen W, Hepp B, et al. (1994) Spinal cord stimulation in Belgium: a nationwide survey on the incidence, indications and therapeutic efficacy by the health insurer. Pain 56: 211-216.

27 Landau B, Levy RM (1993) Neuromodulation techniques for medically refractory chronic pain. Annu Rev Med 44: 279-287.

28 North RB, Kidd DH, Farrokhi F, Piantadosi SA (2005) Spinal cord stimulation versus repeated lumbosacral spine surgery for chronic pain: a randomized, controlled trial. Neurosurgery 56: 98-106.

29 Taylor RS (2006) Spinalcordstimulation in complex regional pain syndrome and refractory neuropathic back and leg pain/failed back surgery syndrome: results of a systematic review and meta-analysis. J Pain Symptom Manag 31: 13-19.

30 Taylor RS, Van Buyten JP, Buchser E (2005) Spinal cord stimulation for chronic back and leg pain and failed back surgery syndrome: a systematic review and analysis of prognostic factors. Spine 30: 152-160.

31 Turner JA, Hollingworth W, Comstock BA, Deyo RA (2010) Spinal cord stimulation for failed back surgery syndrome: outcomes in a workers' compensation setting. Pain 148: 14-25.

32 Van Buyten JP, Van Zundert J, Vueghs P, Vanduffel L (2001) Efficacy of spinal cord stimulation: 10 years of experience in a pain centre in Belgium. Eur J Pain 5: 299-307.

33 Van de Kelft E, de La Porte C (1994) Long-term pain relief during spinal cord stimulation. The effect of patient selection. Qual Life Res 3: 21-27.

34 Ohnmeiss DD, Rashbaum RF (2001) Patient satisfaction with spinal cord stimulation for predominant complaints of chronic, intractable low back pain. Spine J 1: 358-363.

35 Mekhail NA, Mathews M, Nageeb F, Guirguis M, Mekhail MN, et al. (2011) Retrospective review of 707 cases of spinal cord stimulation: indications and complications. Pain Pract 11: 148-153. 
36 Cameron T (2004) Safety and efficacy of spinal cord stimulation for the treatment of chronic pain: a 20-year literature review. J Neurosurg 100: 254-267.

37 Quigley DG, Arnold J, Eldridge PR, Cameron H, Mclvor K, et al. (2003) Long-term outcome of spinal cord stimulation and hardware complications. Stereotact Funct Neurosurg 81: 50-56.
38 Bendersky D, Yampolsky C (2013) Is spinalcordstimulationsafe? A review of itscomplications. World Neurosurg 11: 1878-8750.

39 Colombo EV, Mandelli C, Mortini P, Messina G, De Marco N, et al. (2015) Epidural spinal cord stimulation for neuropathic pain: a neurosurgical multicentric Italian data collection and analysis. Acta Neurochir (Wien) 157: 711-720. 